\title{
Knowledge and Practice of Nutritionists in Management of Type 2 Diabetes Mellitus with Honey: A Case of Hospitals in Nairobi County
}

\author{
Barwecho Mercy $(\mathrm{M}, \mathrm{Sc})^{*}$ \\ Kenyatta National Hospital, Nutrition Department, P.O. Box 20723-00202, Nairobi, Kenya \\ Thaimuta Zakayo (Ph.D) \\ Department of Human Pathology, University of Nairobi, P.O. Box 19776-00625, Nairobi, Kenya \\ Imungi Jasper $(\mathrm{Ph}, \mathrm{D})$ \\ Department of Food Science, Nutrition and Technology \\ University of Nairobi, P.O. Box 29053-00625, Nairobi, Kenya
}

\begin{abstract}
Diabetes mellitus (DM) is a group of metabolic disorders characterized by chronic hyperglycaemia, due to defects in insulin secretion, action activity or both. The prevalence of DM in Kenya is at 3.3\% and is reported to be rising. Administration of drugs, healthy eating and exercises are the recommended management of the disease. Combining anti-diabetic drugs with natural remedies including honey has been reported to be more effective than use of drugs alone. However many Kenyans are sceptical about the use of honey in the management of DM on account of its high sugar. The prescription of honey for management of DM by the medical personnel is therefore viewed with cynicism. This study was therefore designed to assess the knowledge and practice of use of honey in diabetes management by the nutritionists working in hospitals. The study was cross-sectional, involving 57 practicing nutritionists drawn from different departments of public and private hospitals within Nairobi County, and the heads of the nutrition departments as key informants. Data was collected by administering a structured questionnaire to the consenting respondents. The study was granted approved by Kenyatta National Hospital (KNH)/ University of Nairobi (UoN) Ethics and Research Committee. Results showed that up to $50.9 \%$ of the respondents do not have knowledge on the use of honey in the management of DM, while $42.1 \%$ indicated having the knowledge. The gains indicated by the respondents who had knowledge included lowering glycaemic index (7\%), control of blood glucose $(19.3 \%)$, medicinal value (7\%), and provision of energy $(3.5 \%)$, alternative sweetener $(1.8 \%)$ and antioxidant $(1.8 \%)$. Only $19.3 \%$ of the respondents were aware of studies on use of honey in DM management. Most of the nutritionists recommend unprocessed honey (94.1\%) The common forms of usage of the honey were indicated as spreads on bread (41.2\%), sweetener of foods such as tea and porridge $(17.6 \%)$, solution in hot water $(11.8 \%)$ and direct eating $(5.9 \%)$. The quantity of honey recommended one teaspoon $(41.2 \%)$, two teaspoons $(29.4 \%)$, three teaspoons $(23.5 \%)$ and four teaspoon $(5.9 \%)$. Nutritionist who did not recommend honey based their arguments on such reasoning as honey raising blood glucose $(60 \%)$, lack of knowledge on efficacy $(20 \%)$, ignorance $(17.5 \%)$ and patient's non-acceptance $(2.5 \%)$. The study concludes that knowledge among nutritionists on the use of honey in management of type-2 $\mathrm{DM}$ is very low and therefore prescription/recommendation also very limited.
\end{abstract}

Keywords: Nutritionist, Knowledge and Practice, use of honey, Type-2 Diabetes management

DOI: $10.7176 / \mathrm{FSQM} / 91-06$

Publication date:October $31^{\text {st }} 2019$

\section{Introduction}

Diabetes mellitus (DM) is a metabolic disorder characterized by chronic hyperglycaemia, due to defects in insulin secretion, action activity or both (American Diabetes Association, 2011). Diabetes mellitus (DM) is a major cause of morbidity and mortality worldwide (Roglic and Unwin, 2010). Approximately 200 million people suffer from DM worldwide (Bahrami, 2009) and the number is predicted to increase to more than 380 million by 2025. This situation is exacerbated by the estimated number of people with impaired glucose tolerance (IGT), currently at 314 million or $8.2 \%$ in the adult population, and expected to increase by 2025 to 472 million or $9.0 \%$ (WHO, 2012). Type-2 diabetes constitutes about $85 \%$ to $95 \%$ of all diabetes cases in developed countries and accounts for even higher percentage in developing countries. The prevalence of DM in Kenya is $3.3 \%$ (IDF, 2007) and is said to be increasing rapidly. The disease is managed through the administration of drugs, healthy eating and exercises. In spite of these efforts, most of DM patients develop diabetic complications. The doctrine of DM management has been that of maintaining low blood glucose. Elevated blood glucose is infinitely associated also with factors leading to obesity and cardiovascular disease (Tricia, 2011). These factors have been observed to reduce when honey is used in the management of DM (Tricia, 2011). 
Honey is composed of fructose (38\%), glucose (31\%) primarily, and other sugars. However, it also contains more than 180 substances, including minerals, amino acids, vitamins, enzymes and phytochemicals, some of which probably have antidiabetic function (Al-Jabri, 2005; Perez, 2002). The composition of honey varies according to its floral source and origin (Lusby, 2002). A study by Erejuwa (2001) indicated that combining antidiabetic drugs with honey in DM management has beneficial effects. Erejuwa observed that administration of honey increase serum levels of insulin, while it reduced serum concentrations of fructosamine and glucose in diabetic rats (Erejuwa, 2011). It has been established that antiglycemic agent: glibenclamide and metformin when administered in combination with honey resulted in much lower glycemic levels (Erejuwa, 2011). This combination also resulted to lower biochemical parameters such as serum fructosamine, bilirubin, triglycerides, creatinine and very low-density lipoprotein (VLDL) cholesterol in the diabetic rats (Erejuwa, 2011). The effects were not observed when either of the antidiabetic agents was applied alone (Erejuwa, 2011). The same study further showed that the antidiabetic drugs in combination with honey enhanced antioxidant (flavonoids, phenolic acids, amino acids, proteins, and some enzymes) defences, reduced oxidative damage in pancreas and the kidney of diabetic rats (Erejuwa, 2011). In brief, though data are still limited to facilitate concrete conclusions, these studies indicate that honey could be used as an adjunct therapy for DM to achieve better glycaemic control, improve metabolic derangements and prevent oxidative stress linked to DM complications (Erejuwa, 2011).

Use of honey in management of DM has not been adopted in Kenya although few people use it as alternative to sugar. Progressively, the development of modern beekeeping in Kenya has become a very important component of the livestock sub-sector, particularly in the arid and semi-arid areas where effectively other forms of agriculture cannot be sustained (Farouk, 2012). The demand for honey in Kenya is high and producers are challenged to increase their capacity. Honey has a high market value especially in the export market. Health observing consumers are more aware of honey therapeutic properties, used to make a variety of foods and also used as food preservative (Farouk, 2012). According to a study by Farouk (2007) in northern Kenya honey production is expanding in Kenya, though data on production processing, trends and marketing is fragmented (Farouk, 2007). Annual production is estimated at 700 metric tons (Farouk, 2007). The arid and semi-arid lands yield only crudely processed honey for urban market. Introduction of better technology hives can significantly improve the yields and quality of bee products. Local marketing systems should be strengthened through organization of traders and bee-keepers to improve processing and quality assurances enhancing market competitiveness (Farouk, 2007).

\section{Methodology}

The study subjects included nutritionists in health facilities within Nairobi County. There were 57 nutritionists recruited from the purposively selected hospitals as follows: KNH, 44; Mbagathi District Hospital, 10; Nairobi Hospital, 3; Aga Khan University Hospital, 3 and 2 from Mater Hospital. The data was collected using pre-coded questionnaires, recorded and analysed using IBM SPSS statistics. The eligibility criterion included trained and practising nutritionists managing diabetic patients. The following sampling frame was applied to include all the nutritionists (figure 1). 


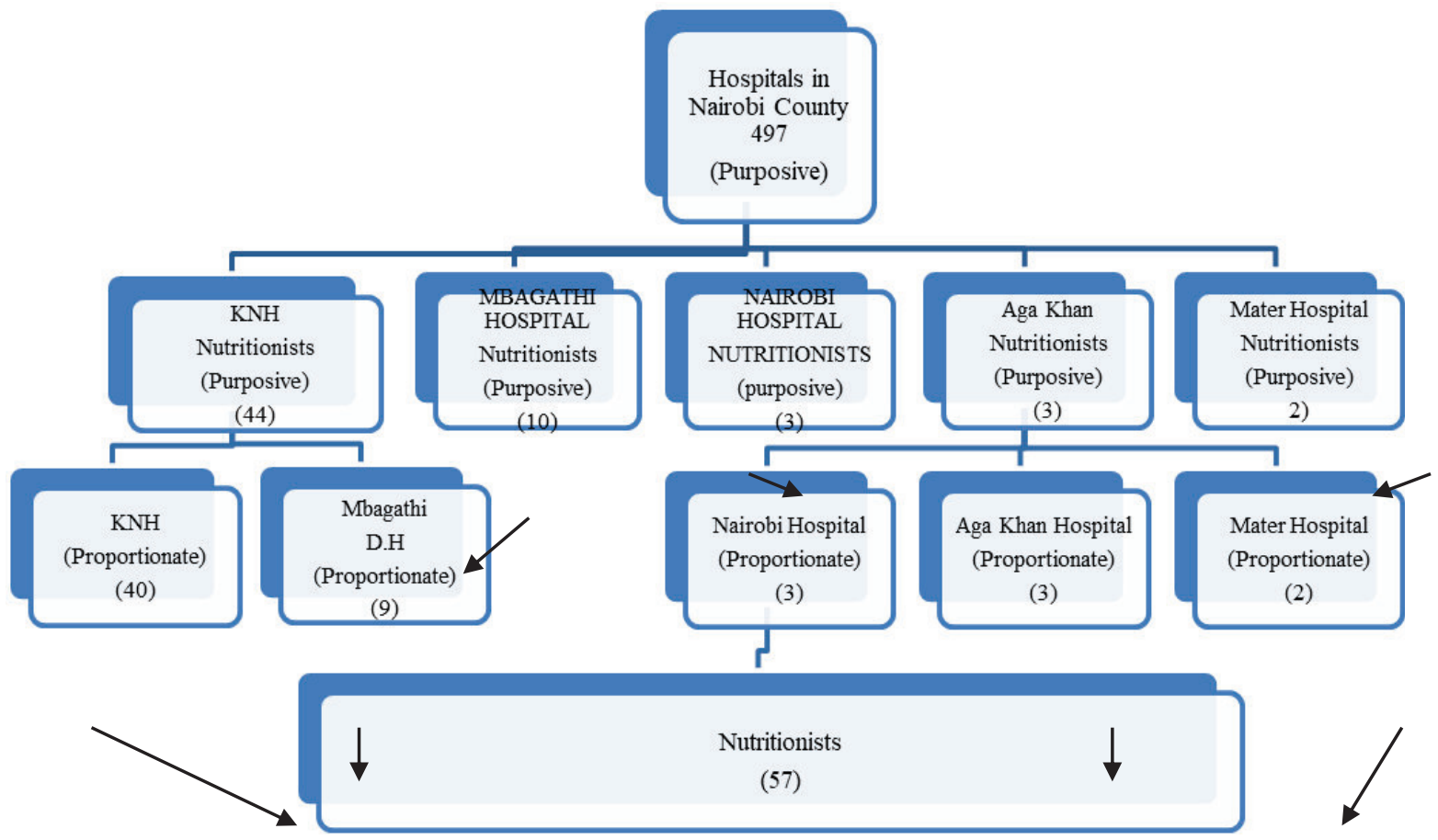

Figure 1: Schematic presentation of sampling procedure on selected hospitals

\section{Results}

Sex of the Nutritionists

Of the 57 nutritionists involved in the study, only $26.3 \%$ were males while the rest were females. The male to female ratio of the study respondents was 1:2.8, Table 1 .

\section{Table 1: Distribution of the Nutritionists by Gender}

\section{Gender}

$\begin{array}{lr}\text { Male } & 26.3 \\ \text { Female } & 73.7\end{array}$

Male: Female ratio

\section{Age of the Nutritionists}

A total of 57 nutritionists participated in the study. Of these $49.1 \%$ were aged between $36-45$ years. Distribution of the nutritionists by age is shown in Table 2 .

Table 2: Distribution of the Nutritionists by Age

$$
\text { Age }
$$

$$
\begin{array}{r}
18-25 \\
26-35 \\
36-45 \\
46-55 \\
>55
\end{array}
$$

\section{Percentage}

$$
\begin{array}{r}
8.0 \\
22.8 \\
49.1
\end{array}
$$

\section{Years of Professional Practice}

Most of participants had professional practice of between $11-15$ years representing $36.8 \%$ and those who had practiced for up to 5 years were at $26.3 \%$. The bulk of nutritionists were from public hospitals at $87.7 \%$ and the rest from private hospital at $12.3 \%$. Distribution of nutritionists by years of professional practice is shown in Table 3 
Table 3: Distribution of Nutritionists by Years of Professional Practice Years of professional practice

Percentage

$\begin{array}{ll}1-5 & 26.3 \\ 6-10 & 5.3 \\ 11-15 & 36.8 \\ 16-20 & 14.1 \\ >20 & 17.5 \\ \text { Total } & 100.0\end{array}$

\section{Clinical Section in the hospital for Practice by Nutritionists}

Most of the respondents (38.6\%) were found practicing in medical wards while $17.5 \%$ were in pediatrics and the rest in different sections areas as shown in Figure 2.

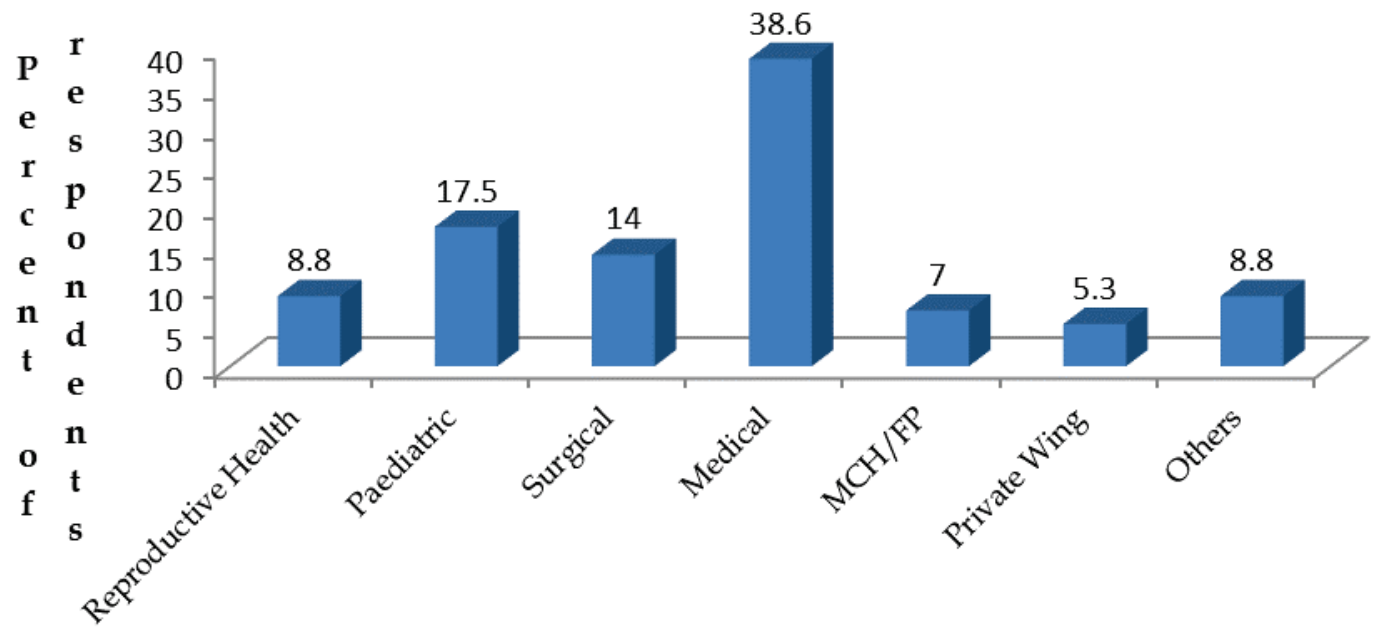

Figure 2: The Clinical Section in the hospital for Practice by Nutritionists

Knowledge and Perception of Nutritionists on Honey in Management of Type-2 DM

Up to $50.9 \%$ of the respondents do not consider honey to have benefits to type 2

DM management and $42.1 \%$ considered honey to have benefits to the patients. The results showed that only $7 \%$ do not know whether honey has benefits or not. Perception of the nutritionists was established in the respondents who demonstrated knowledge on honey benefits. Distribution of nutritionists on perception on the benefits of honey is shown in Figure 3.

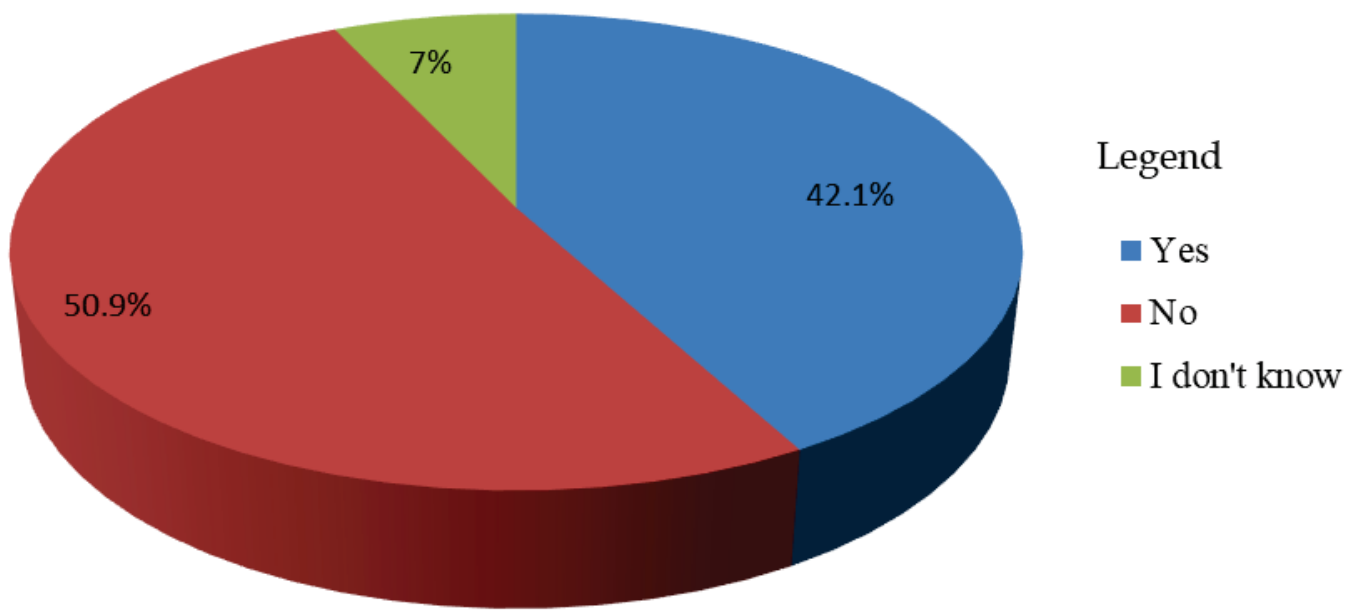

Figure 3: Knowledge and Perception of Nutritionists on the Benefits of Honey to Type 2 DM 
Awareness of Low Glycaemic Index of Honey by Nutritionists

Only $26.3 \%$ of the nutritionists felt that honey has low glycaemic index and controls the blood glucose level, and $7 \%$ felt that it had some form of medicinal value. These results are shown in Figure 4.

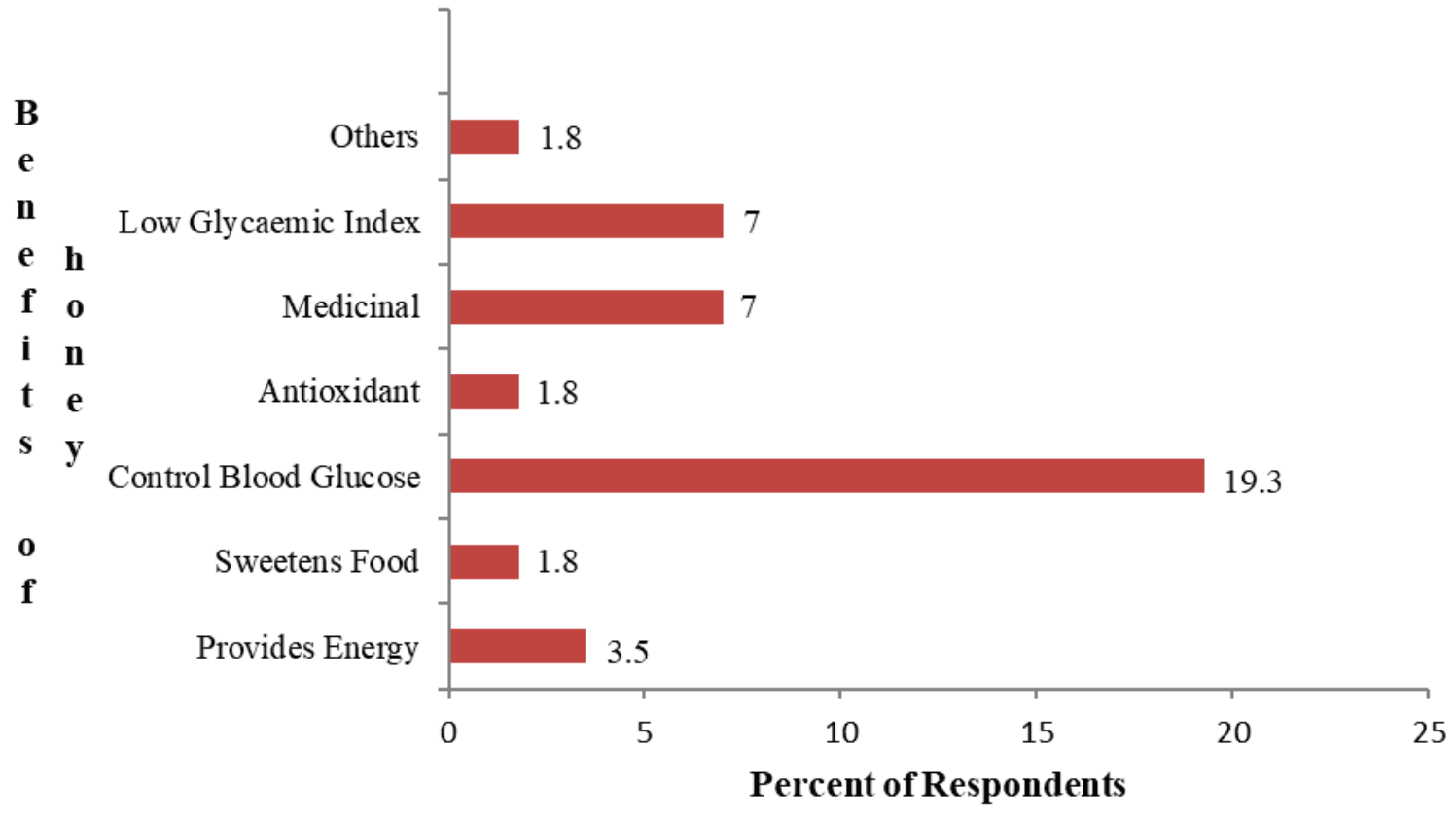

Figure 4: Awareness of Low Glycaemic Index of Honey by Nutritionists

\section{Knowledge of studies done on Honey}

Majority $(80.7 \%)$ of the nutritionists did not know of studies done on benefits of honey on type 2 DM. Only $19.3 \%$ were aware of such studies.

Practice of Nutritionists in Management of Type 2 DM using Honey

This section contains results of the nutritionist's practice on use of honey in the management of type 2 DM.

\section{Use of Honey in Management of Type 2 DM}

Most nutritionists (70.2\%) do not use honey in management of type 2 DM, only $29.8 \%$ applied honey in management of this condition.

\section{Type of Honey Recommended and Advice on Use}

The common form of honey recommended for use by majority of the nutritionists $(94.1 \%)$ was unprocessed honey the rest $5.9 \%$ recommending processed honey. Most of the nutritionists using honey (41.2\%) advised on using it as spreads. Distribution of the nutritionists advising on different ways of using honey is shown in Figure 5. 


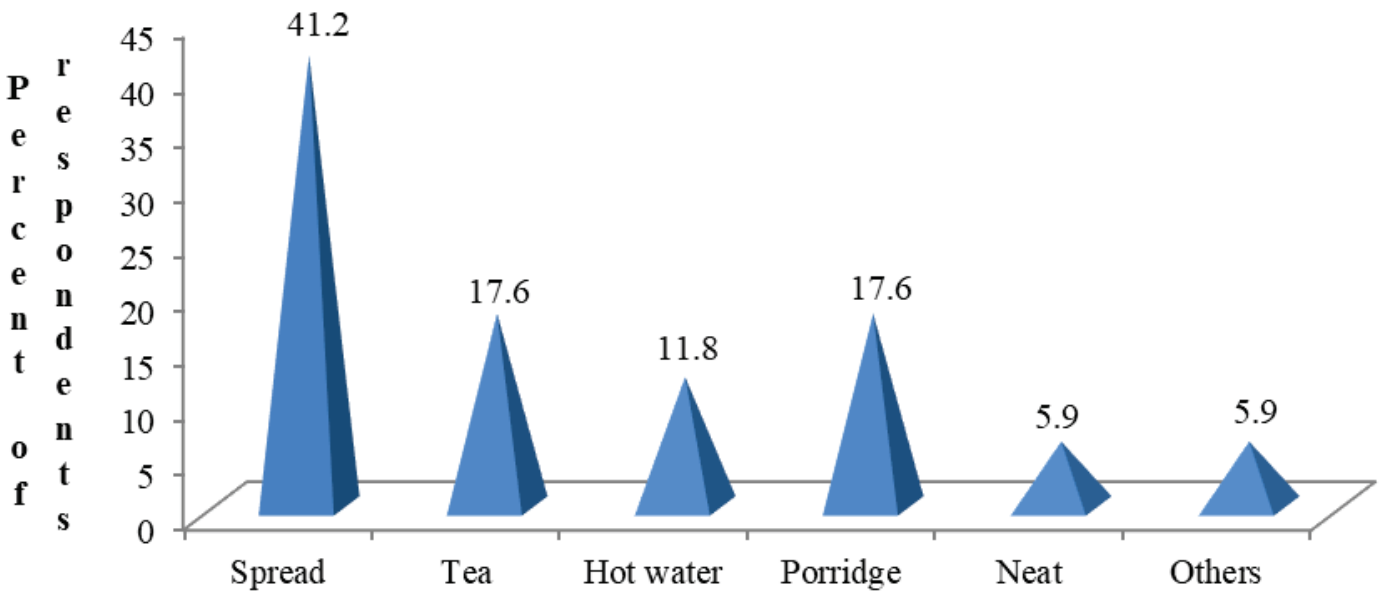

Figure 5: Different Forms of honey use as management food for DM

Reasons for Using Honey in Management of Type 2 DM

The respondents who recommended use of honey in type $2 \mathrm{DM}$ management indicated reasons as raising the blood glucose were $82.3 \%$. Distribution of reasons for using honey in management of type $2 \mathrm{DM}$ is shown in Figure 6.

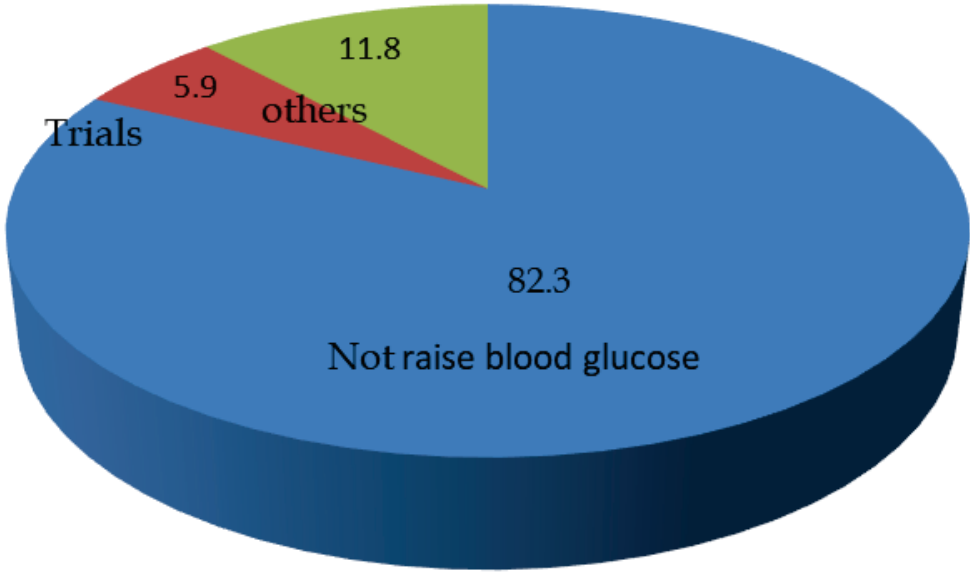

Figure 6: Reasons for using honey in Management of Type 2 DM

\section{Drivers for Use of Honey}

An estimated $58.8 \%$ of nutritionists who recommended use of honey were motivated by studies published in journals, desire of patients at 35.3\% and attendance of seminars at 5.9\%. These results are shown in Figure 7. 


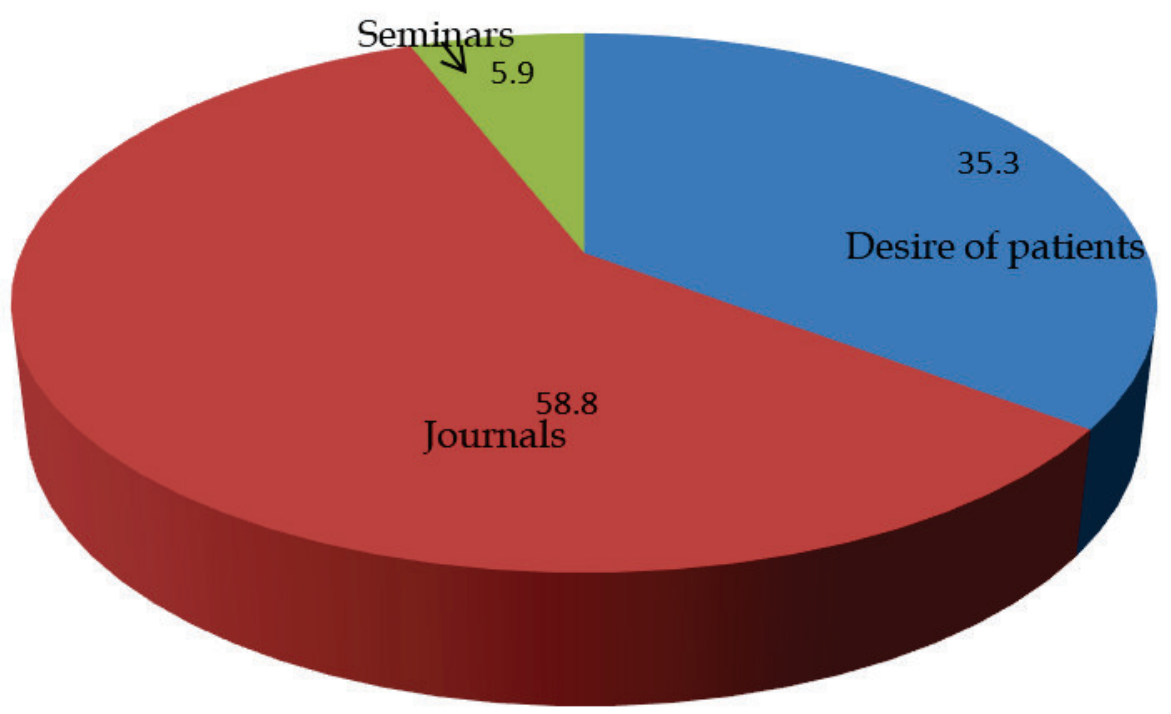

Figure 7: Drivers for Use of Honey

\section{Quantity of Honey Prescribed}

The common amount of honey prescribed by nutritionists per day was 1 teaspoon at $41.2 \%$ and commonly recommended to be taken in the morning. Range of quantities of honey quantities prescribed is shown in Figure 8.

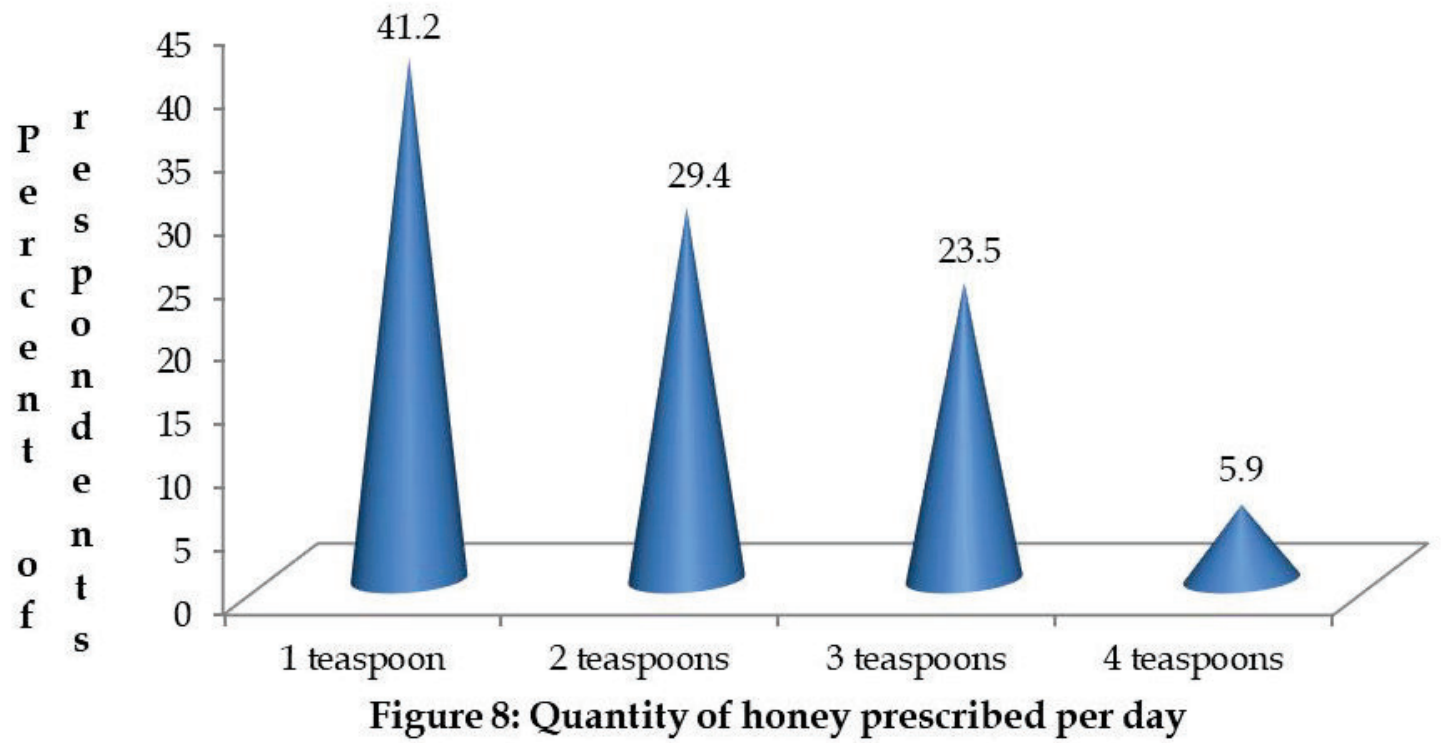

Schedule of Honey Intake and Review

Up to $47.4 \%$ of the nutritionists recommended morning hours as the time of taking honey and $64.7 \%$ of the nutritionists reviewed honey use on the appointment day. Distribution of schedule of honey use and review is shown in Table 4. 
Table 4: Schedule of Honey Intake and Review

\begin{tabular}{lcll}
\hline Scheduled honey intake & Percentage & Reviews & Percentage \\
\hline Morning & 47.4 & Daily & 5.9 \\
Morning and Evening & 47.4 & Weekly & 11.8 \\
Others & 5.2 & Monthly & 17.6 \\
& & Appointment & 64.7 \\
Total & 100 & & 100
\end{tabular}

Reasons for not recommending Honey for Management of Type 2 DM

Up to $60 \%$ of the nutritionists advanced reasons for not recommending honey in management of type 2 DM as fear of raising the blood glucose. Distribution of reasons for not recommending honey for management of type 2 DM is shown in Figure 9.

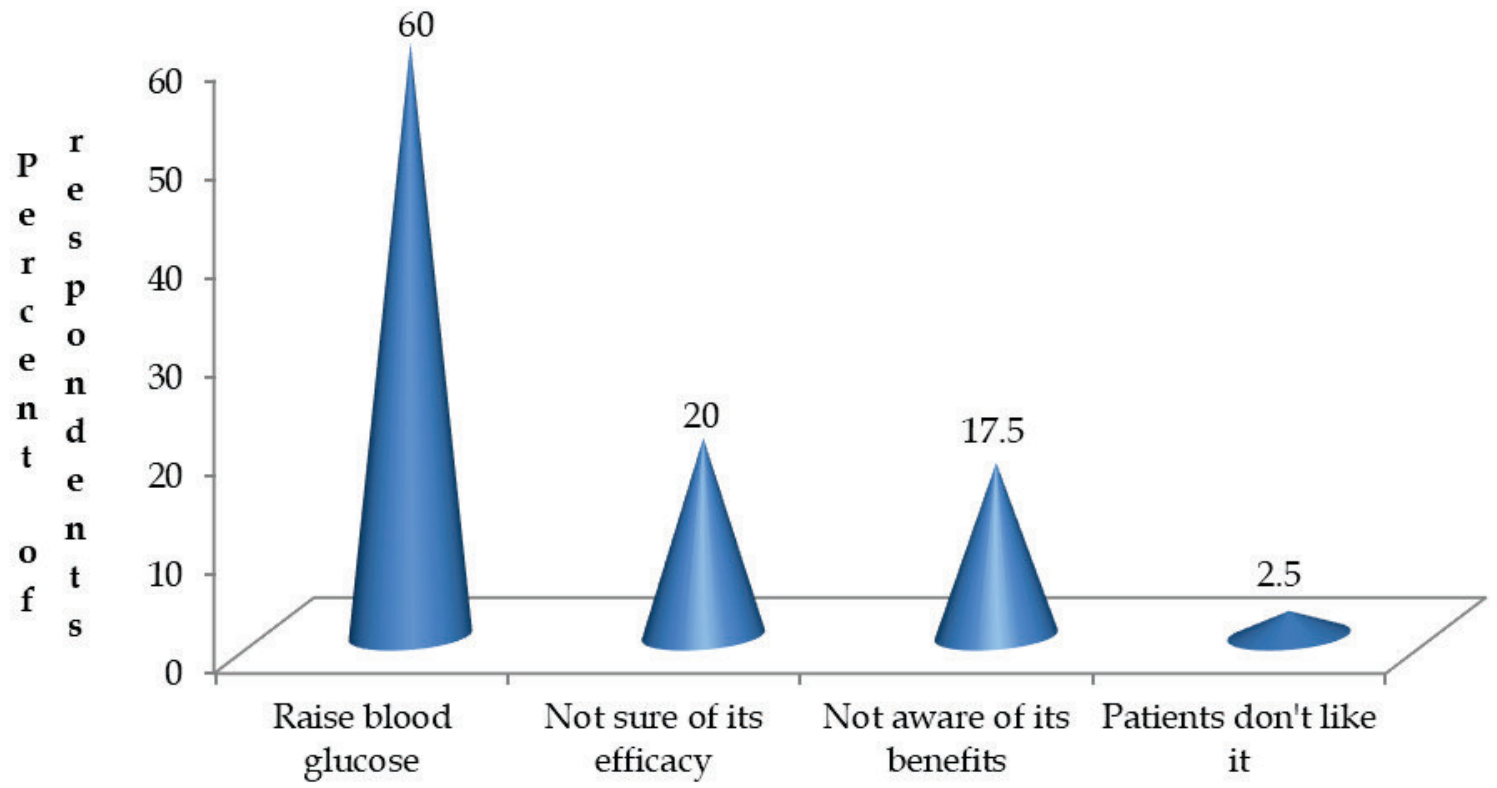

Figure 9: Reasons for not recommending honey

Opinion and Reaction of Nutritionist if found Type 2 DM patients using Honey

On personal opinions of nutritionists, they were asked if they can administer honey in management of type 2 DM and $40.4 \%$ gave the opinion that they will administer honey while $45.6 \%$ will not use which were comparable. Only 14\% were indifferent or no opinion as shown in Figure 10. Most of the study participant would discourage type $2 \mathrm{DM}$ patients from using honey to manage their condition. The approach by nutritionists towards type 2 DM patient using honey include, counsel against use, search literature about honey, check postprandial blood glucose after honey use and educate on dangers of honey use. 


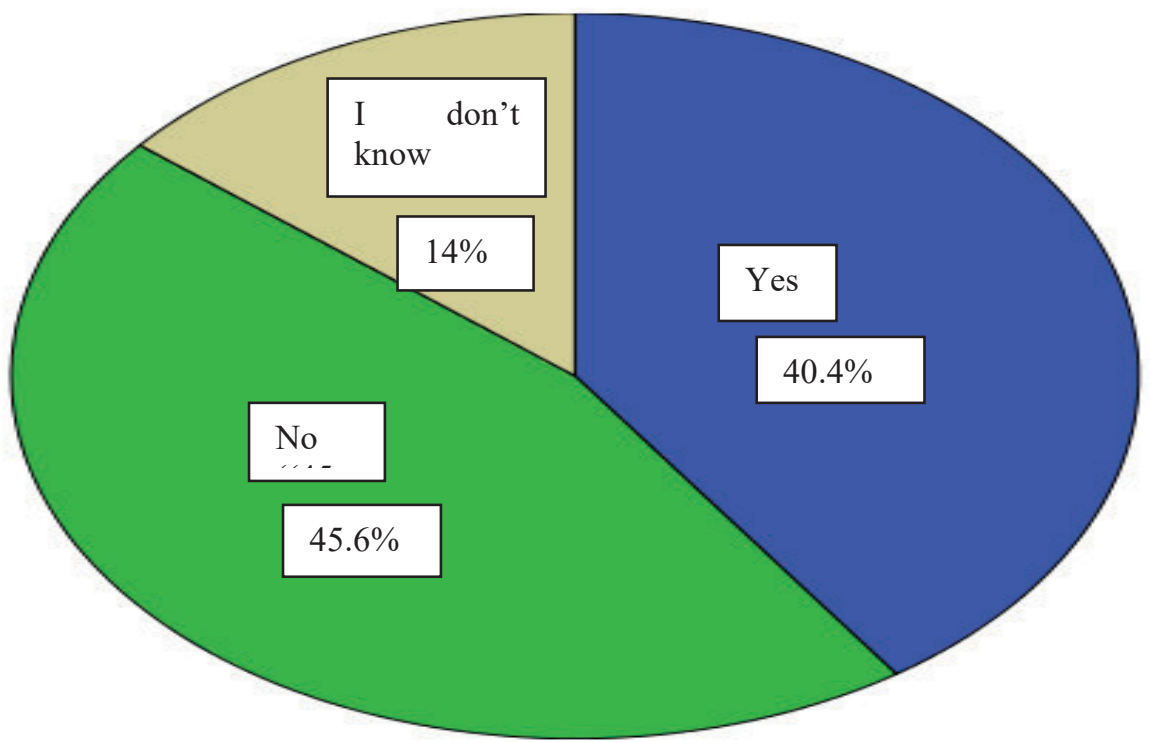

Figure 10: Opinion on Use of Honey in Management of Type 2 DM

\section{DISCUSSION}

The study was undertaken to assess the knowledge and practice of nutritionists in management of type 2 diabetes mellitus using honey. This study recruited 57 nutritionists conducted among the most professionally experienced and trained nutritionists with exposure from the top private and public hospitals across Nairobi County with diversified clinical experiences. Therefore, the study group was representative of knowledge and practice in type 2 DM management within the city. Most of the participants had practised nutrition over 10 years and majority had achieved education level of basic degree. Most of the participants were drawn from medical department (wards and medical outpatient clinics) where most of type 2 DM patients are commonly attended. Other clinical area of operation of respondents was paediatric, surgical, reproductive health and MCH/FP. It shows that each one of them must have witnessed any alternative remedies prescribed to patients of DM in the hospitals.

This study established that more than half of participants do not consider honey to have benefits on type 2 DM management especially when it has such high levels of glucose and fructose which ideally should raise blood sugar levels. All the same, the few who used the honey believed that it has beneficial effects in controlling blood glucose and lowering glycaemic index by mechanisms that they were not able to understand. Other benefits of honey that were indicated include provision of energy, food sweetening and as anti-oxidants. Analysis have shown that honey contains more than 180 substances, including minerals, amino acids, vitamins, enzymes and phytochemicals, some of which probably have antidiabetic functions (Al-Jabri, 2005; Perez, 2002). The composition of honey varies according to its floral source and origin (Lusby, 2002). It would therefore be interesting to see how the control of DM with honey varies with the floral source. Literature indicates that the effects of honey include a lowering of serum glucose, and biochemical substances such as bilirubin, creatinine, triglycerides and very low density lipoprotein (VLDL) which are known to improve metabolic derangement and minimize oxidative stress commonly associated with DM complications (Orejuwa, 2012). More than tw-thirds of the participants in the study do not find any benefit in use of honey in type 2 DM management, representing a large knowledge variance. Generally nutritionists have been taught that sugar causes hyperglycaemia and that is why they are not able to believe that honey which contains mainly glucose and fructose can have the opposite effect. Studies done on use of honey by type-2 DM patients indicate that honey lowers blood glucose levels (Orejuwa, 2012). It is possible the non-sugar components of honey do the lowering of the lowering of the blood sugar levels, but why mainly when used with the chemical antidiabetic drugs? Controlled studies need to be carried out to establish this phenomenon and the very common use of sugar can be exploited to advantage in the management of DM.

Studies done on other foods have indicated presence of antidiabetic properties (Kunyanga et al., 2011; Kunyanga et al., 2011 a; Kunyanga et al., 2011 b; Kunyanga et al., 2012). Some of the foods in these studies included sweet potato, amaranth vegetables, pumpkin, groundnuts, sunflower seeds, pigeon peas and field beans which contain carbohydrates capable of elevating sugar levels in diabetic patients. It is no wonder then that honey should have the antidiabetic properties. The anti-oxidant effects of honey (Gheldof, 2002) should contribute to the antidiabetic effect as the disease is oxidation mediated. The mechanism for the hypoglycemic effect of honey is, however, not well understood. Honey is a mixture of sugars - fructose $(38.5 \%)$ and glucose 
$(31.0 \%)$, maltose, sucrose and other complex carbohydrates. Consequently, it would be expected that consumption of honey would raise the blood sugar and that in fact the glycemic index of honey should advent that of glucose. Finding in several studies that honey causes a reduction in blood glucose levels in both nondiabetic and diabetic patients is an indication that honey has a mechanism, probably insulin sensitization effect (Al - Waili, 2004). Honey supplementation in diabetic patients also showed increased level of insulin concentration (Aronoff, 2004) and reduced insulin resistance (Katsilambros, 1988). Studies done with streptozotocin (STZ) induced diabetic rats using diets supplemented with honey also showed improvement in pancreatic islets (Erejuwa, 2011).

Optimal glycaemic control maintenance remains the main goal of diabetes management. However this goal is difficult to attain as it requires the use of multiple anti-diabetic drugs in perfect balance (Turner, 1999). Glycaemic control deteriorates in diabetic patients with time (Cook, 2005). Research findings show the role of oxidative stress in the origin of $\beta$-cell dysfunction advancing to the inability of pancreatic $\beta$-cells to secrete adequate insulin to satisfactorily recompense for insulin resistance (Drews, 2010). It has also been demonstrated that honey has an adjunct to anti-diabetic drugs, improves glycaemic control and metabolic derangements as well as mitigate cellular oxidative stress, which would be of great interest in the management of diabetes mellitus (Drews, 2010).

However, some studies raise a number of interesting questions and debatable issues. These include: are the observed effects of honey exclusive to a particular honey? Could these findings be generalized to other honey samples that originated from other parts of the globe or country? To be able to adequately address these questions, it would be vital to have data that compare the effects of various honey of diverse origin in diabetes mellitus (Fasanmade, 2003) which current literature lacks such studies. However, in the absence of such data, the few but limited available data implicate that these beneficial effects in preventing impaired metabolism are not restricted to specific honey. Studies from several honey samples from other parts of the world have been shown to reduce hyperglycaemia and ameliorate metabolic abnormalities in diabetic rats (Fasanmade, 2003), type 1 and type 2 diabetic patients (Al-Waili, 2003). It is notable to state that majority of these studies investigated the acute effects of honey on metabolic derangements and hyperglycaemia. This is important as a number of studies have shown that honey considerably reduced postprandial hyperglycaemia but data establishing the marked effect of honey on overall glycaemia (measured by HbA1c) are limited (Abdulrhman, 2011).

Comparative metabolic studies by Bantle (2000)of the glycaemic response to sugars consumption in persons with DM with iso-caloric (having similar caloric values) consumption of other sources of carbohydrate, the postprandial glycaemic response to various forms of carbohydrate $(42 \mathrm{~g}$ separately of glucose, fructose, sucrose, potato starch, and wheat starch) that mixed meal composed $25 \%$ of total energy containing also protein and fat concluded that fructose ingestion resulted to a lower postprandial glycaemic response in diabetics, but the other forms of carbohydrate had nearly identical reactions. The addition of sucrose in short-term trial did not adversely affect glucose control if accounted for on an iso-caloric basis (Colagiuiri, 2001). The American Diabetes Association (ADA) expert panel analysed 22 studies addressing this issue and concluded that, sucrose does not affect glycaemic control in DM significantly from other carbohydrates when ingested in iso-caloric quantities (Franz, 2002). The recommendation is that sucrose be substituted for other carbohydrates if consumed (Franz, 2002).

However, those who recommend use of honey feel that it's useful in unprocessed state. Study by Noori (2004) showed that fresh, unprocessed honey stimulates antibody production and improves and restores the immune system. The common application is through spread or use as food additive. Other applications of honey found in this study included; dissolving in hot water, scooping neat and combining it with lemon tea.

The total amount of starches or carbohydrates in a food is the key consideration and not the amount of sugar (National Honey Board, 2014). Honey is a carbohydrate food as well, just like rice, potatoes, thus 1 tablespoon of honey has approximately 17 grams of carbohydrate and $64 \mathrm{Kcals}$, and taking that into account when counting total daily intake of carbohydrates, diabetics can work it out like any other sweetener or carbohydrates (National Honey Board, 2014). To monitor response to honey, blood sugar levels could be noted before and two hours later after consumption. Also, when purchasing commercial honey for diabetic patients, it should be pure and not adulterated with added glucose, starch, cane sugar, and even malt, which is suspected to be the practice by local small scale processors.

This study established that majority of the practising nutritionists do not know of studies done on honey use in management of type $2 \mathrm{DM}$. The users of honey were correlated with the benefits of honey which was found to be statistically significant. It seems that there was less effort on search of studies on honey in the management of type $2 \mathrm{DM}$ by the nutritionists. In Kenya nurses and nutritionists rarely read around their area of specialization and therefore they are very poorly up-dated. According to a study by Doyle and Ward (2001), individual behaviour is driven by a multitude of influencing factors emanating from personal knowledge, attitudes and beliefs as well as confidence in one's ability to perform particular health behaviour. Also Katzenellenbogenet (2005) in another study found that there is a weak connection between knowledge, attitudes, beliefs and 
behaviour but significant relationship between knowledge and practice, attitudes and practice. In support of the findings, Green and Kreuter (1991) explained that health knowledge is necessary before a sensible personal health action can occur. The desired health action will probably not occur unless a person receives a clue strong enough to spark the motivation to act on that knowledge.

There is no policy on honey use in management of type 2 DM in the country. This could account for the lack of awareness about the use of honey in the management of DM or any disease condition.

It was established in this study that those who recommend honey use to type 2 DM patients were driven by knowledge from scientific journals, patient's desire and scientific seminars attended. The common dosage was 1 to 2 teaspoon per day, commonly taken by whatever method including direct sucking, in the morning or morning and evening. It was established that there was no consistent review by nutritionists of patients who were on honey prescription for management of type $2 \mathrm{DM}$. This was probably because the prescription was not official and at the discretion of the nutritionist. The review was done dependent of DM clinic appointment date. Most of the clinics review their patients after 1 to 3 months period. The review for 1 to 3 months of honey use is not effective measure of efficacy of honey in the management of type $2 \mathrm{DM}$. This is because the effects of honey on blood glucose levels are instantaneous. It therefore follows that even those using honey in management of type 2 DM lose out on its gains through lengthy period of review.

The study established that most of practitioners who do not recommend honey believed it will increase blood glucose, no known benefits and its efficacy. This is not consistent with the literature information. The reasons advanced for non-use of honey are driven personal opinions, feelings or attitudes. However, this is consistent with results in this study that most participants do not know of any reports on honey use in type 2 DM management. It was also observed that there were no hospital guidelines on use of honey. This was expected because guidelines are drawn from policies. There are no policies on honey use in management of disease

\title{
Conclusions
}

The study revealed that there are nutritionists who are familiar with the management of type 2 diabetes with honey probably emanating from reading and interaction with colleagues during their longstanding experience in practice. The study established, however that, that nutritionists had limited knowledge on the use of honey in management of type $2 \mathrm{DM}$, which probably accounted for the prescriptions or recommendations of honey for use in DM management. There are no policy guidelines for use of honey in management of DM in the Country or hospitals.

\author{
Abbreviations used \\ DM: $\quad$ Diabetes Mellitus \\ KNH: Kenyatta National Teaching, Research and Referral Hospital \\ MCH/FP: Maternal and Child Health/ Family Planning
}

\section{Acknowledgements}

The authors are grateful to Hospitals within Nairobi County for enabling environment for the study, Nutritionists for cooperation throughout the study and $\mathrm{KNH} / \mathrm{UON}$ ERC for authorization of the study.

\section{References}

Abdulrhman M., Akhtar M.S, Kha M.S, (2011). Glycaemic responses to three different honeys given to normal and allxan-diabetic rabbits. Journal Pakistan Medical Association, 39: 107-13.

Abdulhman M., El-Hefnawy M., Hussein R., (2011). The glycemic and peak incremental indices of honey, sucrose and glucose in patients with type 1 diabetes mellitus: effects on C-peptide level-a pilot study. Actadiabetol, 48: 89-94.

Abdulrhman M., El-Hefnawy M., Ali R, El-Goud A.A., (2011). Honey and type 1 diabetes mellitus. InType 1 diabetes - complications, pathogenesis, and alternative treatments. Edited by CP L. Croatia: InTech, 228233.

Al-Jabri A., Al Mahrooqi z., Nzeako B., Nsanze H., (2005). Inhibition effect of honey on the adherence of Salmonella to intestinal epithelial cells in vitro. International Journal Food Microbiology, 103(3): 347-351.

Al-Waili N., (2003). Intrapulmonary administration of natural honey solution, hyperosmolar dextrose or hypoosmolar distill water to normal individuals and to patients with type-2 diabetes mellitus or hypertension: their effects on blood glucose level, plasma insulin and C-peptide, blood pressure and peaked expiratory flow rate. European Journal of Medical Research, 8:295-303.

Al-Wali, N.S. (2004). Natural honey lowers plasma glucose, C-reactive protein, homocysteine, and blood lipids in healthy, diabetic, and hyperlipidemic subjects: comparison with dextrose and sucrose. Journal of Medicinal Food, 7(11):100-7

American Diabetes Association, (2011). Diagnosis and classification of Diabetes Mellitus. Diabetes Care, 34 
(Supplement 1): S62-9.

American Diabetes Association, Sherwin R.S., (2011). Type 2 diabetes mellitus. In: Goldman L, Schafer AI, eds. Goldman's Cecil Medicine. 24th edition. Philadelphia, Pa.: Elsevier Saunders, 33: 158-10.

Aronoff S.L., Berkowitz K., Shreiner B., (2004). Glucose metabolism and regulation: beyond insulin and glucagon. Diabetes Spectrum. 17: 183-90.

Bahrami M., Ataie-Jafari A., Hosseini S., Foruzanfar M. H., Rahmani M. and Jajouhi M., (2009). Effects of natural honey consumption in diabetic patients: an 8-week randomized clinical trial. International Journal of Food Science and Nutrition, 60(7): 618-626.

Bantle J., Laine D., Castle G., (2000). Postprandial glucose and insulin responses to meals containing different carbohydrates in normal and diabetic subjects. New England Journal of Medicine ;309:7-12.

Bee keeping technical handbook (2010). A publication of the national beekeeping station, Ministry of livestock development republic of Kenya.

Cook M. N., Girman C.J., Stein P.P., Alexander C.M., Holman R.R., (2005). Glycemic control continues to deteriorate after sulfonylureas are added to metformin among patients with type 2 diabetes. Diabetes Care, 28:995-1000.

Colagiuiri S., Miller J., Edwards R., (2001). Metabolic effects of adding sucrose and aspartame to the diet of subjects with NIDDM. Am erican Journal of Clinical Nutrition; 50:474-8.

Doyle E.,Ward S., (2001). The process of community health education and promotion. Long Grove, Illinois: Waveland Press.

Drews G., Krippeit-Drews P., Dufer M., (2010): Oxidative stress and beta-cell dysfunction. Pflugers Arch: European Journal of Physiology, 460: 703-718.

Erejuwa O.O, Sulaiman S.A., Wahab M.S., Sirajudeen K.N., Salleh M.S., Gurtu S., (2011): Glibenclamide or metformin combined with honey improvesglycemic control in streptozotocin-induced diabetic rats. International Journal of Biological Science, 7: 244-252.

Erejuwa O.O., Gurtu S., Sulaiman S.A., (2010). Hypoglycaemic and antioxidant effects of honey supplementation in streptozotocin-induced diabetic rats. International Journal of Vitamin and Nutrition Research, 80: 74-82.

Erejuwa O.O., Gurtu S., Sulaiman S.A., AbWahab M.S., Sirajudeen K.N., Salleh M.S., (2010): Hypoglycemic and antioxidant effects of honey supplementation instreptozotocin-induced diabetic rats. International Journal of Vitamin and Nutrition Research, 80: 74-82.

Erejuwa O.O., Sulaiman S.A., Wahab M.S., (2011). Glibenclamide or metformin combined with honey improves glycemic in streptozotocin-induced diabetic rats. International Journal of Biological Science, 7: 244-52.

Erejuwa O.O., Sulaiman S.A., Wahab M.S., (2012). Fructose might contribute to the hypoglycaemic effect of honey. Molecules, 17: 1900-15.

Erejuwa O.O., Sulaiman S.A., Wahab M.S., (2012). Fructose might contribute to the hypoglycemic effect of honey. Molecules, 17: 1900-1915.

Erejuwa O.O., Sulaiman S.A., Wahab M.S., Salam S.K., Salleh M.S., Gurtu S., (2011). Hepatoprotective effect of tualang honey supplementation instreptozotocin-induced diabetic rats. International Journal of Applied Research in Natural Product, 4: 37-41.

Erejuwa O.O., Sulaiman S.A., Wahab M.S., Salam S.K., Salleh M.S., Gurtu S., (2011). Effect of glibenclamide alone versus glibenclamide and honey on oxidative stress in pancreas of streptozotocin-induced diabetic rats. Internal Journal of Applied Research in Natural Product, 4: 1-10.

Erejuwa O.O., Sulaiman S.A., Wahab M.S., Salam S.K., Salleh M.S., Gurtu S., (2011). Comparison of antioxidant effects of honey, glibenclamide, metformin, and their combinations in the kidneys of streptozotocin-induced diabetic rats. International Journal of Molecular Sciences, 12: 829-843.

Erejuwa O.O., Sulaiman S.A., Wahab M.S., Sirajudeen K.N., Salleh M.S., Gurtu S., (2010). Antioxidant protection of Malaysian tualang honey in pancreas of normal and streptozotocin-induced diabetic rats. Annals of Endocrinology (Paris), 71: 291-296.

Erejuwa O.O., Sulaiman S.A., Wahabi M.S., (2012). Hepatoprotective effect of tualang honey supplementation in streptocin-induced diabetic rats. International Journal of Applied Research in Natural Products, 4: 37-41.

Fasanmade A, Alabi O., (2003). Differential effect of honey on selected variables in alloxan-induced and fructose-induced diabetic rats. African Journal of Biomedical Research, 11:191-196.

Farouk J., (2007). Awarded the inaugural One-to-Watch Bryden Alumni Award by York University, Toronto, Canada, in November 2005, for his work with Honey Care Africa.

Franz M., Bantle J., Beebe C., (2002). Evidence-based nutrition principles and recommendations for the treatment and prevention of diabetes and related complications. Diabetes Care, 25:148-98.

Gheldof N, Wang X, Engeseth N (2002). Identification and quantification of antioxidant components of honeys from various floral sources. Journal of Agricultural Food Chemistry, 50: 5870-7.

Green L.W., Kreuter M., (1991). Health promotion planning: An educational and environmental approach. 2nd 
edition. Mountain View: Mayfield Publishing Company.

IDF 2007. Diabetes Atlas 3rd Edition. International Diabetes Federation.

Katsilambros NL, Philippides P, Touliatou A, Georgakopoulos K, Kofotzouli L, Frangaki D et al. (1988). Metabolic effects of honey (alone or combined with other foods) in type II diabetics. Acta Diabetologica Latina 25, 197-203.

Katzenellenbogen J.M., Joubert G., Abdool S.S., (2005). Epidemiology: A manual for South Africa. Cape Town: Oxford University Press.

Kunyanga C.N., Imungi J.K., Okoth M., Momanyi C., Biesalski H.K., (2011). Antioxidant and antidiabetic properties of condensed tannins in acetonic extract of selected raw and processed indigenous food ingredients from Kenya. Journal of food science, 76: 560-567

Kunyanga C.N., Imungi J.K., Okoth M., Momanyi C., Biesalski H.K.,Vadivel V., (2011a). Antioxidant and type 2 diabetes mellitus related functional properties of phytic acid extract from Kenyan local food ingredients: Effects of traditional processing methods. Ecology of food and nutrition, 50:452-471.

Kunyanga C.N., Imungi J.K., Okoth M., Momanyi C., Biesalski H.K.,Vadivel V., (2011b). Flavonoid content in ethanolic extracts of selected raw and tradionally processed indigenous foods consumed by vulnerable groups of Kenya: antioxidant and type II diabetes-related functional properties. International Journal of Food Sciences and Nutrition, online: 1-9.

Lusby P.E., Coombes A., Wilkinson J.M., (2002). Honey: A potent agent for wound healing? Journal of Wound Ostomy and Continence Nursing, 29: 295-300.

National Honey Board. Carbohydrates and the Sweetness of Honey". Last accessed 1 November, 2014.

Noori S. Al-Waili, Afruz H., (2004). Effect of Honey on Antibody Production against Thymus-Dependent and Thymus-Independent Antigens in Primary and Secondary Immune Responses. Journal of Medicinal Food, 7(4): 491-494.

Perez R.A., Sanchez-Brunete C., Calvo R.M., Tadeo J.L., (2002). Analysis of volatiles from Spanish honeys by solidphasemicroextraction and gas chromatography-mass spectrometry. Journal of Agricultural Food Chemistry, 50(9): 2633-2637.

Razquin C., Martinez J.A., Martinez-Gonzalez M.A., (2009). 3 years follow-up of a Mediterranean diet rich in virgin olive oil is associated with high plasma antioxidant capacity and reduced body weight gain. European Journal of Clinical Nutrition, 63: 13-19.

Roglic G., Unwin N., (2010). Mortality attributable to diabetes: estimates for the year 2010. Diabetes Research and Clinical Practice, 87: 15-9.

Turner R.C., Cull C.A., Frighi V., Holman R.R., (1999). Glycemic control with diet, sulfonylurea, metformin, or insulin in patients with type 2 diabetes mellitus: progressive requirement for multiple therapies (UKPDS 49). UK Prospective Diabetes Study (UKPDS) Group. Journal of the American Medical Association, 281:2005-2012.

Tricia M.N., Erin G.C., Allison F., Marsa G., Amy L., Harley P., Lauren M., Kelly J.L., Mark K., (2011). Honey promotes lower weight gain, adiposity and triglycerides than sucrose in rats. Nutrition Research, 31 (1): 55 60.

WHO (2002). The World Health Report 2002: Reducing Risks, promoting healthy life. World Health organization, Geneva. 